\title{
Green Human Resource Management Practices and Environmental Performance in Ghana: The Role of Green Innovation
}

\author{
Isaac Ahakwa ${ }^{*}$, Jingzhao Yang ${ }^{2}$, Evelyn Agba Tackie ${ }^{\mathbb{D}}$, Mercy Asamany 4
}

1,2,3 School of Management, Jiangsu University, Zhenjiang, People's Republic of China

4 Information Services Department, Obuasi Municipal Assembly, Obuasi, Ghana

* Corresponding author: isaacahakwa@gmail.com

\begin{abstract}
Article History
Received 2021-08-15

Revised 2021-09-18

Revised 2021-10-23

Accepted 2021-10-24

Published 2021-10-26
\end{abstract}

\section{Keywords}

Environmental performance

Green recruitment and selection

Green Compensation

Green Innovation

Ghana

How to cite?

Abakwa, I., Yang, J., Tackie, E. A., \& Asamany, M. (2021). Green Human

Resource Management Practices and

Environmental Performance in Ghana: The

Role of Green Innovation. SEISENSE

Journal of Management, 4(4), 100-119.

doi: $10.33215 /$ sjom.v4i4.704
Purpose- Protecting the natural environment and its wealth for future generations has become an essential topic for policymakers and executives. This study seeks to examine the impact of green Human Resource Management practices through green innovation on the environmental performance of small and medium-sized manufacturing enterprises in Ghana.

Design/Methodology- Through simple random probability sampling, data were obtained from three hundred (300) business owners and employees from ten (10) small and medium-sized manufacturing enterprises in the Greater Accra Region of Ghana. However, two hundred and ninety-four (294) accurate responses were used in the analysis due to incomplete and missing figures. Data were analyzed using partial least squared based on Structural Equation Modeling (SEM).

Findings- The studied data met internal consistency reliability, convergent, and discriminant validity from the results, and also, there was no multicollinearity issue in the study model. The findings revealed that green Human Resource Management practices directly and significantly influence environmental performance. Furthermore, green innovation partially mediated the influence of green Human Resource Management practices on environmental performance. Green compensation through green innovation has the most incredible impact on environmental performance and was statistically significant at $\mathrm{p}<0.01$.

Practical Implications- This finding provides valuable suggestions for policymakers, emerging and existing organizations, particularly manufacturing firms, to encourage environmentally-friendly activities and produce goods and processes through a successful incentive scheme, thus increasing customer loyalty. 


\section{Introduction}

Environmental sustainability has emerged in recent decades as one of the world's most pressing concerns. Protecting the natural environment and its wealth for future generations has become an essential topic for policymakers and executives (Hameed et al., 2020). Stakeholders such as consumers and employees recently requested companies to improve environmental accountability (Yuriev et al., 2018). That has generated more stress and motivated business organizations by taking environmentally sustainable practices and processes (Saeed et al., 2018). Jabbour and de Sousa Jabbour (2016) postulated that building and enforcing green management practices is competitively advantageous. Many organizations are trying to establish and incorporate a structured environmental management system to achieve this growth. Dumont et al. (2017) clarified that green initiatives are the main green human resources management (GHRM) practices that require action on the part of employees to help achieve organizations' green objectives. Therefore, GHRM practices are essential for employees to participate in green initiatives in line with the organization's vision (Pham et al., 2020). Since the organization plays an active role in attaining sustainable growth, many scholars have focused on connecting human resources management (HRM) and environmental management by underlining the value of green workforce management in businesses. Therefore, GHRM is the alliance of HRM with environmental management, which helps companies improve environmental performance (EMP) by enhancing employee environmental engagement (Rawashdeh, 2018). GHRM in corporate companies has become critical as human resources departments work to foster businesses' green culture by maintaining green offices and green practices. GHRM is an indispensable strategic tool to meet companies' sustainability goals.

There is a rising outcry concerning environmental degradation owed to industrial operations in manufacturing areas worldwide, and environmental issues are reportedly widespread (Bour et al., 2019a; Bour et al., 2019b). In various manufacturing industries, organic and inorganic waste are mainly released into the environment. That includes acids, extremely toxic minerals like mercury or arsenic, or organic poisonous substances. Such environmental injustices may have detrimental consequences; insecure water for home use and even irrigation. The toxins can reach the alimentary chain and cause human health problems (Chan and Hsu, 2016). The 2020 Environmental Performance Index (EPI) ranked Ghana at $168^{\text {th }}$ out of 180 countries with 27.6 on 32 performance indicators across 11 issue categories covering environmental health and ecosystem vitality. This finding reveals that Ghana is not doing well in environmental protection issues compared to other countries. Manufacturing activities contribute a greater percentage to this problem. Hence, this calls for effective environmental management policies and practices to be formulated and implemented by all institutions to improve Ghana's environmental performance. Unfortunately, the literature concerning environmental performance, particularly in the Ghanaian context, is of minimal quality, considering the significance and complexity of these problems. This study will give organizations in Ghana indigenous empirical evidence to create and implement environmentally friendly policies and practices that lead to environmental sustainability. In this regard, this study aims to analyze the value of greening HRM practices and examine the effect on the environmental performance of small and medium-sized manufacturing enterprises in Ghana.

As a result, several studies have investigated the relevance of GHRM on EMP. For example, Gilal et al. (2019) explored the nexus amid GHRM practices and EMP in Pakistan's higher education institutions. Their findings indicated that GHRM practices had a favorable impact on EMP due to employees' environmental zeal. They also claimed that when employees are deeply invested in environmental principles, the effect of GHRM practices on environmental ardor becomes critical. Also, Rawashdeh (2018) explored the link between GHRM practices and EMP in the health sector of Jordan. Their findings revealed a strong positive linkage between GHRM practices and EMP. Their findings also revealed a considerable adoption of GHRM in health institutions, with the highest link between recruiting and selection and the slightest correlation between training and development. Singh et al. (2020) conducted a study on GHRM practices and EMP in the manufacturing 
sector of the United Arab Emirates. They discovered that GHRM activities through green innovation (GI) impact a firm's EMP.

Furthermore, Sobaih et al. (2020) evaluated the association amid GHRM practices, GI, and EMP in Egypt's small lodging firms. The investigators discovered that owner-managers green ability, motivation, and opportunity directly, positively, and substantially influenced organizational GI and EMP. They proposed that the ability of owner-managers is one of the most effective GHRM practices for GI and EMP. The results once again displayed that when GI was introduced, the effect of GHRM activities on EMP was doubled, demonstrating the importance and essential significance of GI in EMP. Yafi et al. (2021) looked at the interaction between GHRM practice and EMP in Malaysia, and their research found that green training had a material impact on EMP. Further investigations between the variables were performed in Bahrain (Ahmed et al., 2019). The study found a positive connection between GHRM practices and EMP with employee engagement mediating the link between the two variables.

Based on the above highlights, the current study explores the role of GHRM practices on EMP of small and medium-sized manufacturing enterprises in Ghana, considering the role of GI. This study adds to existing knowledge by employing covariates like green recruitment and selection, green compensation, green training and development, green innovation, and EMP. This study contributes to the extant literature on GHRM activities and EMP in the Ghanaian context and has been grouped into the following categories: First, the study extends the limited research on understanding the role of GHRM practices on EMP. This current study is among the first to consider these variables in the Ghanaian context. Second, the analytical procedures used in this study differ significantly from earlier studies. The study employed "PLSpredict" in assessing the predictive relevance of the study's model due to its robustness. PLSpredict is the current technique to assess the predictive relevance (Shmueli et al., 2019). Most previous studies on EMP did not use this more effective estimator. Last, numerous studies on EMP have been undertaken. None withstanding, this study considered the issue of common method bias (CMB) as opposed to the numerous studies done in this field but did not consider issues of CMB. According to Kock (2015), a probable cause of CMB is the implicit societal attraction related to responding to questions in a survey using a unique procedure that causes the variables to bear a certain amount of similar variations. The issue of CMB was solved in this research by providing appropriate reliability evidence, factor structures, convergent, and discriminant validity as suggested by Conway and Lance (2010). Again, variance inflation factor (VIF) assessment of collinearity proposed by Kock (2015) was performed to equally salvage the $\mathrm{CMB}$ issue in this research.

The following is the procedure the rest of the study took: the empirical literature supporting the study is given in the "Literature Review" part. The "Methodology" portion represents the method of the research. The empirical findings are outlined in the "Research Results" section, and the final section of the study is the discussion, policy implication, limitations, and recommendations.

\section{Literature Review}

\section{Environmental Performance}

Organizational performance is defined as the outcome of all organizations' activities and can be measured by analyzing their current actions concerning their effectiveness and productivity (Ghosh et al., 2017). The resource-based theory claims that cooperation can be successful by managing organizational resources to produce positive outcomes and become the market leader (Singh et al., 2019). Organizational environmental performance refers to the execution of policies that positively impact the environment. Therefore, businesses are actively invited to implement appropriate environmental management policies to benefit from environmental conservation (Jabbour and de Sousa Jabbour, 2016). Many businesses have adopted tactical 
environmental performance programs to achieve a competitive benefit (Alonso-Almeida et al., 2018). Investors trust that ecologically concerned establishments are pricey. Investors argue that customers and the capital market trust green companies; therefore, environmental success will improve corporate performance (Chiu et al., 2020). An organization's and managers' understanding of environmental performance has also increased by a rising figure of environmental laws and market pressure (Raab et al., 2018). From the above discussion, the value of environmental performance is thought to represent an excellent chance to increase the competitive benefits of companies in a win-win state as it is a strategic prospect for organizations to incorporate environmental performance in corporate tactics and to reinvent the process through a green conception (Dangelico et al., 2017). Implementing environmental performance programs has led to several businesses' pollution reduction, greenhouse gas reduction, and hazardous waste reduction (Kim et al., 2019). Only if the organization has the right personnel with the right qualifications can environmental performance be carried out successfully (Kim et al., 2019). Therefore, human resource practices must be associated with corporate strategic objectives.

\section{Green Human Resource Management}

Research reveals that HRM systems have moved from outdated work methods; low personnel interaction levels to more engaging and accommodating phases; thus, workers are motivated to develop talents, knowledge, and approaches (Harrison and Bazzy, 2017). GHRM refers to HRM techniques directed at the economic and environmental effects of enterprises in a period of enhanced awareness of environmental protection and the production of natural resources (Singh et al., 2020; Siyambalapitiya et al., 2018) and is related to an excellent ecological tactic and green activities of employees (Roscoe et al., 2019). We claim that GHRM is a significant part of sustainable HRM literature and reflects healthy environmental management practices. GHRM serves as a platform to relate human resources management practices to environmental management activities (Ansari et al., 2020; Masri and Jaaron, 2017). Green human resources management thus reflects the planned environmental protection direction of the company and calls on senior management to take note of organizational strategies and activities that enable workers to partake in green work habits to minimize environmental pollution at work (Longoni et al., 2018; Singh et al., 2020). Green human resources management entails introducing human resource structures of the enterprise's ecological management goals, including compensation, training and development, and last, recruitment and selection (Cheema and Javed, 2017; Singh et al., 2020).

\section{Green Recruitment and Selection}

Green recruiting and selection (GRS) is considered one of the human resource management activities, offering the prospective employer an incentive to adopt green human resource management initiatives. Seeking and maintaining professional workers is recognized as the world's greatest challenge for human resources managers (Mwita and Kinemo, 2018). Environmentally conservative business entities are marketing themselves to recruit knowledgeable, green-known practitioners who also follow green practices and sustainability issues. On the other side, job searchers train themselves for green culture's international norms as green workers. Green workers prefer organizations with environmental and social responsibility for their core businesses (Chaudhary, 2018). The work analysis process should involve and interact on environmental issues in the job description and job requirements of companies and clearly describe the selected applicant's requirements (Paillé, 2019). The job description should take into account statements clarifying and assuring the relevance of environmental reporting, according to Aranganathan (2018) research findings. Second, inductive preparation should concentrate on providing information on its strategies, principles, and green objectives on Newcomers' environmental conservation. Third, interviews with prospective candidates should be structured for evaluating greening proposals for prospective applicants. Masri and Jaaron (2017) indicated that a leading portion of the interview requirements would interview potential candidates on environmental issues. Arulrajah and Opatha 
(2016) said that businesses could build the necessary support for achieving success in protecting the environment by developing new jobs with an environmental issue or linking environmental tasks to each position's duties environment management aspects of companies in particular. The choice of the best environmentally engaged candidates for company greening initiatives should ensure the shortlisting of applicant quality criteria (Nejati et al., 2017). Past research has shown a substantial impact of GRS on organizations' environmental performance (Kim et al., 2019; Rawashdeh, 2018; Yusoff et al., 2020). The following hypothesis is suggested in light of the above discussion:

H1: Green recruitment and selection have a positive influence on environmental performance.

\section{Green Training and Development}

Green training is one of the greatest significant green human resource activities for green management performance in businesses. Environmental training is an effective technique for human resources development (Aragão and Jabbour, 2017). The goal is to promote the public's attention to environmental issues and their awareness, build an active attitude towards greening initiatives and improve waste reduction and energy saving (Zoogah, 2018). In supporting environmental management system efficiency, Teixeira et al. (2016) insisted that environmental training is immensely functional. Environmental preparation is also crucial for successfully implementing the environmental management framework and developing a green business culture (Teixeira et al., 2016). Mishra (2017) concluded that environmental preparation is essential for systematic low carbon goods production to mitigate climate change. Saeed et al. (2019) have revealed that customized and tailored green employee training is essential for businesses. The usefulness of the training program with an effective instrument is also assessed. Rawashdeh (2018) proposed that some practical methods for environmental conservation, energy management, and safety recycling training, green workplace research, waste handling, environmental training, and programs be integrated into the training programs and the rotation of work by future green managers. These training programs must focus on educational necessities to reach significant environmental benefits through training (Masri and Jaaron, 2017). More academic works have shown significant and positive linkages amid green training and development and environmental performance (Abuelhassan and Elsayed, 2020; Rawashdeh, 2018; Yusoff et al., 2020). The following hypothesis is suggested in light of the above discussion:

H2: Green training and development have a positive impact on environmental performance.

\section{Green Compensation}

The Green Incentive System is a crucial motivator and recognizes its significant environmental output (Teixeira et al., 2016). The goal is to achieve, conserve, and inspire people to achieve good performance and recognize the value of preserving the environment (Rawashdeh, 2018). A green compensation system is when a company aligns its system with its green strategies and practices. It should produce green workplace initiatives, lifestyle initiatives and reduce carbon emissions (Ramasamy, 2017). People need to be compensated for their participation in accepting the growth of environmentally friendly philosophy (Mishra, 2017). This could be a part of the several different incentives that businesses can use to gain green skills. Bonuses can take the form of financial-oriented environmental management awards (for example, premium, cash, bounces), non-financial environmental management rewards (vacation, gifts, study leave bonuses), recognized environmental management (for example, external roles and regular lounges), and constructive environmental management rewards (Arulrajah and Opatha, 2016; Rawashdeh, 2018). All those types of incentives appreciate staff engaged in environmentally friendly practices (Renwick et al., 2013) by identifying and remunerating people committed to the goals of the environment and those managers who inspire employees to carry out eco-friendly initiatives (Arulrajah and Opatha, 2016). Numerous works have established that companies can attain positive environmental performance by contributing various rewards like letters of appreciation, promotions, profits, 
bonuses, money, and gifts (Arulrajah and Opatha, 2016; Rawashdeh, 2018; Saeed et al., 2018). The following hypothesis is suggested in light of the above discussion:

H3: Green compensation has a significant impact on environmental performance.

\section{The Mediating Role of Green Innovation}

Green innovation (GI) applies to the production of environmentally sustainable goods and procedures through the implementation of corporate activities, including greener raw materials, the utilization of smaller amounts of materials throughout the design of products using eco-design philosophies, and the reduction of pollutants, the reduction of water, energy and other raw materials consumption (Dubey et al., 2017). Several previous reports indicate that green innovation companies are incredibly competitive (Albort-Morant et al., 2018). GI companies have more significant average results than their competitors, as they exploit their green capital and ability to react rapidly and appropriately to consumer demands(Allameh and Khalilakbar, 2018) and incorporate intangible assets and wealth. Green innovation and green business performance are strengthened by GHRM (Jia et al., 2018; Singh et al., 2020). Earlier research shows GHRM affects GI (Guerci et al., 2016). Previous research has also proposed that human resource management bundles or structures affect innovation (Feng and Chen, 2018; Fu, 2015; Singh et al., 2020). Human resource management bonds or mechanisms control executive, procedure, and product innovation (2008) and even lower human capital start-ups. Human resource management systems are a significant source of GI (De Winne and Sels, 2010). Human resource management practices focusing on stimulating a philosophy of dedication than compliance positively affect the organization's GI orientation (Singh et al., 2020). Feng and Chen (2018) propose that strategic human resource management positively affects product innovation in companies with a developmental atmosphere and a flat organizational framework.

Moreover, existing literature indicates that the green recruitment and selection method should hire prospective workers based on their environmental values (Roscoe et al., 2019). It will allow new hires to recognize companies' ecological importance and views (Jackson and Seo, 2010) and draw on future employees' beliefs in the Environment (Rawashdeh, 2018). Green training and development and green recompenses and reimbursement are equally critical human resource management activities for promoting environmental efficiency (Jabbour and de Sousa Jabbour, 2016; Singh et al., 2020). We claim that GTD initiatives targeted to progress the skills and institutionalize eco-friendly goals, roles, and performance management system reviews for workers engaged in green place of work research, recycling, waste management, and energy conservation (Singh et al., 2020).

Green innovation is related to a robust environmental sustainability policy, which stimulates environmental performance (Tariq et al., 2019; Varghese, 2019). GI is a planned advantage for environmental success (Karabulut, 2019). Innovating green products and processes significantly reduces the organization's negative impact on the environment and increases business efficiency by reducing waste and costs, saving money, time and energy, financial, environmental, and social success (El-Kassar and Singh, 2019; Singh et al., 2019). Previous research indicates that through constructive corporate intentions and practices to improve environmental efficiency and achieve a strategic advantage; green innovation should not be viewed as reactive steps against stakeholder pressures (Singh et al., 2020; Sobaih et al., 2020). Via GI, we project that GHRM practices directly impact environmental performance. Hence, we propose these:

H4: Green innovation mediates the relationship between green recruitment and selection and environmental performance.

H5: Green innovation mediates the relationship between green training and development and environmental performance. 
H6: Green innovation mediates the relationship between green compensation and environmental performance.

\section{The Conceptual Framework}

Below is the conceptual framework obtained based on the above literature:

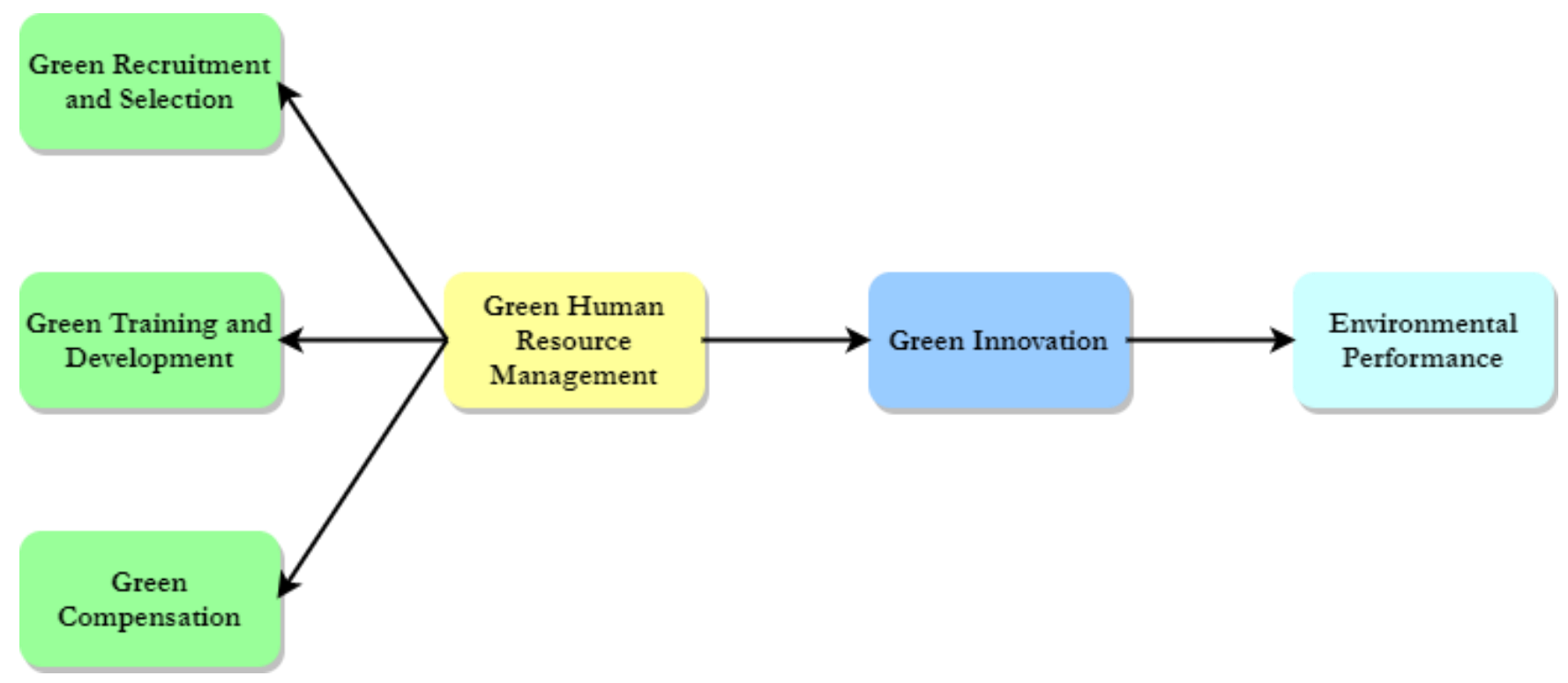

Figure 1: Conceptual framework

\section{Methodology}

The study used quantitative methods to analyze classification features, measure figures, and create a statistical pattern to test hypotheses and clarify findings. The study was conducted in the Greater Accra Region of Ghana. Greater Accra Region has the smallest and medium-sized manufacturing enterprises in Ghana. The study population consisted of business owners and employees working at small and medium-sized manufacturing enterprises in Ghana's most economically viable region, the Greater Accra Region. The primary source of data was used in this study. Primary data was obtained by distributing questionnaires (online survey) to business owners and employees from ten (10) well-known small and medium-sized manufacturing enterprises in the capital region, Greater Accra, Ghana using a Simple Random Sampling technique. Two Hundred and NinetyFour (294) accurate responses were retrieved out of 300 overall survey responses. The remaining six (6) were considered invalid and therefore omitted as they were either substantially incomplete responses or had missing values.

Environmental performance was measured with four items (Daily et al., 2012; Melnyk et al., 2003). Green HRM practices (GTD and GC) were assessed using four items each (Arulrajah and Opatha, 2016; Rawashdeh, 2018). GRS was assessed with three items taken from (Arulrajah and Opatha, 2016; Rawashdeh, 2018). We adapted five items to measure green innovation: three green product innovation items and two green process innovation items (Chen et al., 2006). The items selected were measured on a five-point Likert scale with the scale limits stretching from strongly disagree (1) to strongly agree (5).

The data obtained from the online survey platform was transferred into an excel spreadsheet for easy accessibility and analysis. Both exploratory and confirmatory analyses were carried out on the obtained data to authenticate the validity and reliability of the model. Statistical Package for Social Sciences (SPSS) version 26.0 was used to access the descriptive variables, which are the demographic characteristics of the respondents. 
Structural Equation Model through Partial Least Squares (PLS), SmartPLS version 3 software was used to analyze the study's measurement and structural models. The measurement model evaluated the reliability and validity of the data obtained from the survey through a series of tests. The structural model employed a twostage analytical procedure proposed by Hair Jr et al. (2016) to test the study's hypotheses. The path coefficients of the various hypotheses were assessed through a bootstrapping method (5000 resamples) and the factor loading of each construct (Hair Jr et al., 2016). The model's predictive significance $\left(\mathrm{Q}^{2}\right)$, effect sizes $\left(\mathrm{f}^{2}\right)$, and PLS predict were all assessed to establish the relevancy of the study model.

\section{Research Result}

\section{Respondents Demographic Profile}

Table 1: Respondent's Profile

\begin{tabular}{lcc}
\hline Demographic Characteristics & & $\mathbf{\%}$ \\
\hline \multirow{2}{*}{ Gender } & Male & 72.3 \\
& Female & 27.7 \\
\hline \multirow{3}{*}{ Age } & $18-25$ years & 38.8 \\
& $26-35$ years & 47.2 \\
& $36-45$ years & 9.9 \\
\multirow{2}{*}{ Qualification } & 46 years and above & 4.1 \\
\hline \multirow{3}{*}{ Work Experience } & Diploma certificate & 69.6 \\
& Bachelor degree & 20.9 \\
& Post-graduate degree & 9.5 \\
\hline
\end{tabular}

The demographic characteristics of respondents are one important part of every research. The difference in respondents' demographic information usually determines the essence and approach to address a condition. Several studies, including Wahab and Othman (2021) and Wahab and Tajuddin (2020), assert that demographic characteristics of respondents play a vital role so far as improvement and solving specific situations are concerned. In this study, the respondents' demographic information is derived from owners and employees of small and medium-sized manufacturing firms. The diversity in age, education, and work experience of the sampled population often requires a unique approach in addressing situations. For instance, workers with 5 years of working experiences might be much better in training and development programs in relation to the work compared to workers with less than one-year experience. Thus, the approach of the manufacturing organizations must also differentiate based on respondents' demographic profile to suit and match their current satisfaction and needs. In light of the above discussion, the respondents' demographic profile were discussed.

The descriptive statistics of the respondents presented in Table 1 showed $72.3 \%$ males and the remaining $27.7 \%$ females. Also, 38.8\% of the respondents were between the ages 18 years to 25 years, $47.2 \%$ were between 26 years to 35 years, $9.9 \%$ constituted the ages between 36 to 45 years, whereas the least percentage, which is 4.1 , constituted the age range 46 years and above. Concerning the respondents' working experiences, 3.1\% had not up to one year of experience at their current workplaces, $15.5 \%$ had 1 to 2 years working experience at their current workplaces, $41.2 \%$ had 2 to 5 years of work experience, and $40.2 \%$ had more than 5 years of work experience. Finally, with the respondents' educational background, 69.6\% had obtained a diploma certificate, 
$20.9 \%$ had a certificate of bachelor's degree, and $9.5 \%$ had a post-graduate degree certificate (either a master's degree or a doctoral degree).

\section{Measurement Model Assessment}

Table 2: Assessment of Construct Reliability and Validity

\begin{tabular}{|c|c|c|c|c|c|}
\hline Construct & Notation & Loadings $(\geq 0.60)$ & $\begin{array}{c}\text { Cronbach } \\
\text { Alpha }(\geq 0.70)\end{array}$ & $\begin{array}{c}\text { Composite } \\
\text { Reliability }(\geq 0.70)\end{array}$ & $\begin{array}{c}\text { AVE } \\
(\geq 0.50)\end{array}$ \\
\hline & EMP1 & 0.760 & \multirow{4}{*}{0.799} & \multirow{4}{*}{0.869} & \multirow{4}{*}{0.624} \\
\hline Environmental & EMP2 & 0.798 & & & \\
\hline Performance & EMP3 & 0.821 & & & \\
\hline \multirow{4}{*}{$\begin{array}{l}\text { Green Recruitment and } \\
\text { Selection }\end{array}$} & EMP4 & 0.779 & & & \\
\hline & GRS1 & 0.737 & \multirow{3}{*}{0.772} & \multirow{3}{*}{0.869} & \multirow{3}{*}{0.690} \\
\hline & GRS2 & 0.868 & & & \\
\hline & GRS3 & 0.880 & & & \\
\hline \multirow{4}{*}{$\begin{array}{l}\text { Green Training and } \\
\text { Development }\end{array}$} & GTD1 & 0.852 & \multirow{4}{*}{0.885} & \multirow{4}{*}{0.920} & \multirow{4}{*}{0.742} \\
\hline & GTD2 & 0.853 & & & \\
\hline & GTD3 & 0.910 & & & \\
\hline & GTD4 & 0.821 & & & \\
\hline \multirow{4}{*}{ Green Compensation } & GC1 & 0.841 & \multirow{4}{*}{0.841} & \multirow{4}{*}{0.893} & \multirow{4}{*}{0.676} \\
\hline & GC2 & 0.783 & & & \\
\hline & GC3 & 0.836 & & & \\
\hline & GC4 & 0.828 & & & \\
\hline \multirow{5}{*}{ Green Innovation } & GI1 & 0.710 & \multirow{5}{*}{0.823} & \multirow{5}{*}{0.876} & \multirow{5}{*}{0.586} \\
\hline & GI2 & 0.727 & & & \\
\hline & GI3 & 0.788 & & & \\
\hline & GI4 & 0.789 & & & \\
\hline & GI5 & 0.809 & & & \\
\hline
\end{tabular}

Table 2 presents the assessment of the measurement model, which is also known as the preliminary test assessment. The measurement model assessment employs Factor Loading, Cronbach Alpha, Composite Reliability, and Average Variance Extracted (AVE) to check for the validity and reliability of the data. The factor loadings of the various constructs in Table 2 exceeded the threshold value of 0.6 proposed by Chin et al. (2008).

The Cronbach alpha, which measures the internal consistency of the constructs, exceeded the threshold value of 0.70 (Hair Jr et al., 2016). Also, the composite reliability values are between 0.869 and 0.920 , which far exceeded the threshold value of 0.7 (Hair Jr et al., 2016). The thumb rule for the AVE suggests that its values should not be below the threshold of 0.5 (Hair Jr et al., 2016). In Table 2, it can be seen that the AVE values of the various constructs exceeded 0.5 , which is statistically good for the analysis.

The measurement assessment passed the convergent validity, internal reliability, and construct reliability tests suggesting that the model is good enough for the structural analysis to be carried out, supporting those of Ying et al. (2021), Korankye et al. (2021), and Tackie et al. (2020). 
Table 3: Collinearity Values

\begin{tabular}{lccc}
\hline Construct & Items & VIF (Inner Values) & VIF (Outer Values) \\
\hline \multirow{4}{*}{ Environmental Performance } & EMP1 & & 1.476 \\
& EMP2 & - & 1.666 \\
& EMP3 & & 1.705 \\
Green Compensation & EMP4 & & 1.605 \\
& GC1 & & 1.910 \\
& GC2 & 1.237 & 1.660 \\
& GC3 & & 2.191 \\
Green Innovation & GC4 & & 1.779 \\
& GI1 & & 1.521 \\
& GI2 & \multirow{2}{*}{1.313} & 1.622 \\
Green Recruitment and Selection & GI3 & & 1.883 \\
& GI4 & & 1.703 \\
& GI5 & & 1.856 \\
Green Training and Development & GRS2 & 1.237 & 1.297 \\
& GRS3 & & 2.081 \\
& GTD1 & & 2.228 \\
& GTD2 & \multirow{2}{*}{1.046} & 2.498 \\
& GTD3 & & 2.067 \\
& GTD4 & 2.143 \\
\hline
\end{tabular}

Table 3 present the VIFs valuations of the individual constructs. According to Dormann et al. (2013), the VIF assessment is performed to estimate the connections between a dependent variable and a cluster of independent variables. Grewal et al. (2004) argued that the problem of collinearity occurs when the sample size involved in the survey is insignificant in number. Yet, collinearity is likely to occur if all the study variables have the same linear properties (Dormann et al., 2013). Kim (2019) proposed that if the VIF values are more than 5, there is a collinearity problem with the model, whereas VIF values less than five mean there is no collinearity problem with the model. From Table 3, it is evidenced that all the values of the VIF assessment are lesser than the threshold value signifying that the model has no collinearity problems, supporting those of Ahakwa et al. (2021a) and Odai et al. (2021). Also, the occurrence of a VIF greater than 3.3 is proposed as an indication of pathological collinearity and indicates that the model may be contaminated by CMB. Therefore, if all VIFs resulting from a collinearity test are equal to or lower than 3.3 , the model can be considered free from common method bias (Kock, 2015). Hence our VIFs values in Table 3 suggest that our model is free from CMB, collaborating with Ahakwa et al. (2021b) and Ahakwa et al. (2021c).

Table 4: Fornell-Larcker's Discriminant Validity

\begin{tabular}{lccccc}
\hline Constructs & $\mathbf{1}$ & $\mathbf{2}$ & $\mathbf{3}$ & $\mathbf{4}$ & $\mathbf{5}$ \\
\hline Environmental Performance & $\mathbf{0 . 7 9 0}$ & & & & \\
Green Compensation & 0.540 & $\mathbf{0 . 8 2 2}$ & & & \\
Green Innovation & 0.497 & 0.375 & $\mathbf{0 . 7 6 6}$ & & \\
Green Recruitment and Selection & 0.465 & 0.349 & 0.376 & $\mathbf{0 . 8 3 1}$ & \\
Green Training and Development & 0.248 & 0.057 & 0.208 & 0.078 & $\mathbf{0 . 8 6 2}$ \\
\hline
\end{tabular}

Note: Values on the diagonal (bolded) are the AVE's square root, while the off-diagonals are correlations. 
Table 5: Heterotrait-Monotrait Ratio (HTMT) for Discriminant Validity

\begin{tabular}{lccccc}
\hline Constructs & $\mathbf{1}$ & $\mathbf{2}$ & $\mathbf{3}$ & $\mathbf{4}$ & $\mathbf{5}$ \\
\hline Environmental Performance & & & & & \\
Green Compensation & 0.595 & & & & \\
Green Innovation & 0.658 & 0.432 & & & \\
Green Recruitment and Selection & 0.587 & 0.427 & 0.473 & \\
Green Training and Development & 0.289 & 0.064 & 0.237 & 0.092 \\
\hline
\end{tabular}

Note: Shaded boxes are the standard reporting format for the HTMT procedure.

Table 4 and Table 5 present the discriminant validity, which signifies the degree to which the measures do not reflect other variables. Two different criteria were used to assess the discriminant validity of the model; thus, Fornell-Larcker Criterion propounded by Fornell and Larcker (1981) and the Heterotrait-Monotrait (HTMT) criterion proposed by Henseler et al. (2015). Henseler et al. (2015) believe that the HTMT ratio of correlations is considered more reliable than the Fornell-Larcker Criterion. In presenting both criteria, Table 4 presents Fornel-Larcker's criterion. This criterion shows the square root of the AVE values in diagonal, and according to Fornell and Larcker (1981), the values in diagonal must be larger than its corresponding correlation coefficient. So, from Table 4, it can be seen that all the values in diagonal are larger than their corresponding correlation coefficient, suggesting a satisfactory discriminant validity (Fornell and Larcker, 1981). The HTMT criterion is presented in Table 5. The thumb rule is that when the HTMT value is bigger than 0.85 , there is a discriminant validity problem (Kline, 2011). From table 5, it can be seen that the HTMT values obtained are lesser than 0.85 suggesting the model is free from discriminant validity problems (Tackie et al., 2020).

\section{Structural Model Assessment}

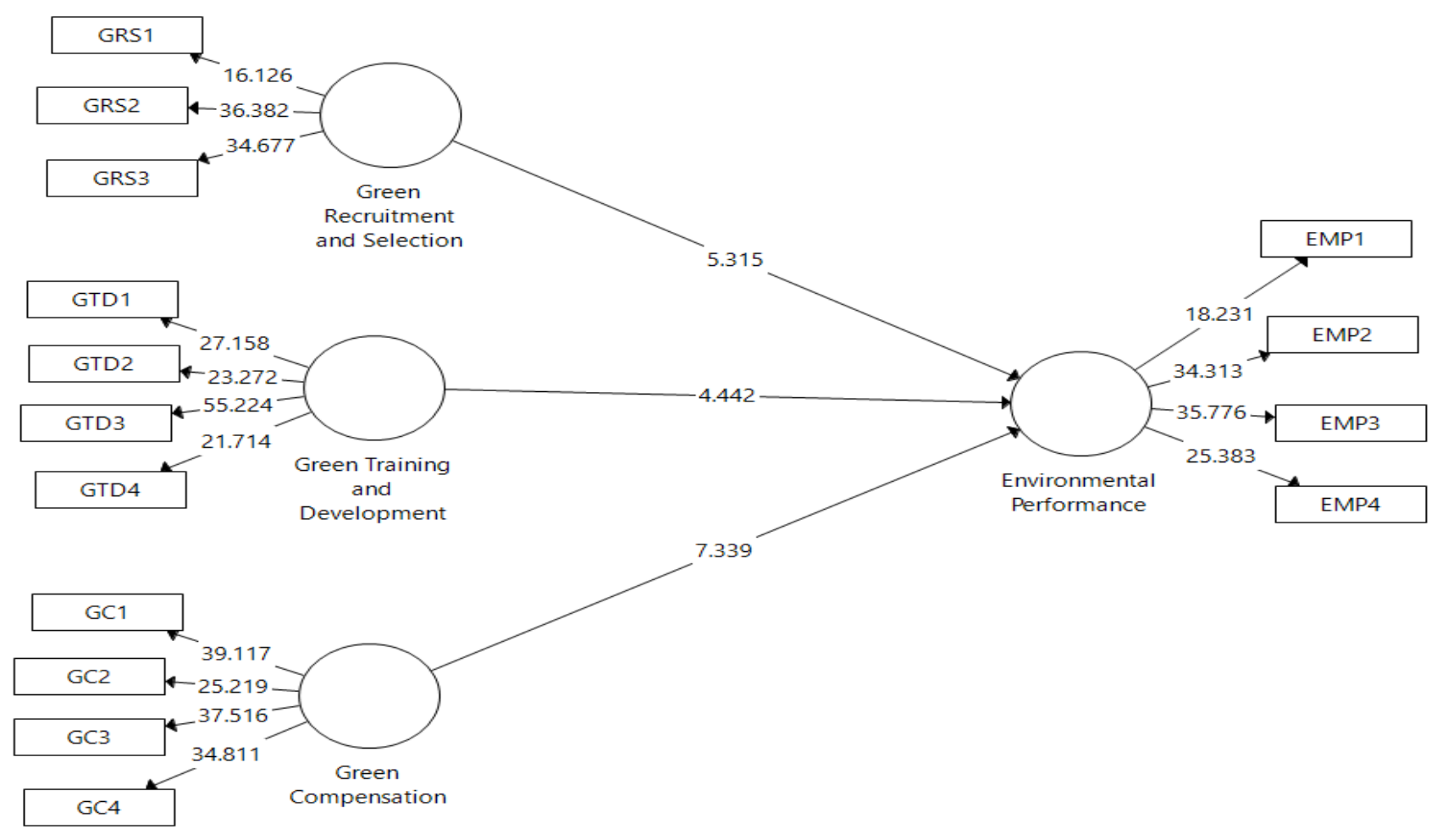

Figure 2: The structural model for direct relationships 
Table 6: Hypotheses Testing (Direct Relationships)

\begin{tabular}{lcccccc}
\hline Relationships & Path & Mean & Std & t-stat & Prob & Decision \\
\hline H1: GRS $\rightarrow$ EMP & 0.322 & 0.323 & 0.061 & 5.315 & $0.000^{*}$ & Supported \\
H2: GTD $\rightarrow$ EMP & 0.196 & 0.198 & 0.044 & 4.442 & $0.000^{*}$ & Supported \\
H3: GC $\rightarrow$ EMP & 0.378 & 0.381 & 0.052 & 7.339 & $0.000^{*}$ & Supported \\
\hline
\end{tabular}

Note: * denotes significance at $1 \%$ level; EMP, environmental performance; GRS, green recruitment and selection; GTD, green training, and development; GC, green compensation, GI, green innovation.

In measuring the structural model, we first assessed the direct relationships between the variables. The results showed that, GRS positively and significantly affected EMP $(\beta=0.322$, t-statistics $=5.315, \mathrm{p}<0.01)$, and GTD positively and significantly affected EMP $(\beta=0.196, t$-statistics $=4.442, \mathrm{p}<0.01)$. GC also positively and significantly affected EMP $(\beta=0.378, t$-statistics $=7.339, \mathrm{p}<0.01)$. Consequently, H1, H2, and H3 were all supported (See Table 6).

Table 7: Indirect Relationship

\begin{tabular}{lccccccc}
\hline Relationships & Path & Mean & Std & t-stat & Prob & Decision & Mediation Type \\
\hline H4: GRS $\rightarrow$ GI $\rightarrow$ EMP & 0.146 & 0.151 & 0.035 & 4.160 & $0.000^{*}$ & Supported & PM \\
H5: GTD $\rightarrow$ GI $\rightarrow$ EMP & 0.093 & 0.097 & 0.030 & 3.054 & $0.002^{*}$ & Supported & PM \\
H: GC $\rightarrow$ GI $\rightarrow$ EMP & 0.152 & 0.157 & 0.037 & 4.121 & $0.000^{*}$ & Supported & PM \\
\hline
\end{tabular}

Note: * denotes significance at 1\% level; PM, partial mediation; EMP, environmental performance; GRS, green recruitment and selection; GTD, green training, and development; GC, green compensation, GI, green innovation.

Second, we assessed the indirect relationships by measuring the mediating effects of the constructs. GI positively and significantly mediated the relationship between GRS and EMP $(\beta=0.084$, t-statistics $=3.667, \mathrm{p}<$ $0.01)$, and GI positively and significantly mediated the association between GTD and EMP $(\beta=0.053, t$-statistics $=2.809, \mathrm{p}<0.01)$. GI also positively and significantly mediated the connections between GC and EMP $(\beta=$ 0.085, t-statistics $=3.498, \mathrm{p}<0.01)$. Therefore, H4, H5, and H6 were all supported (See Table 7).

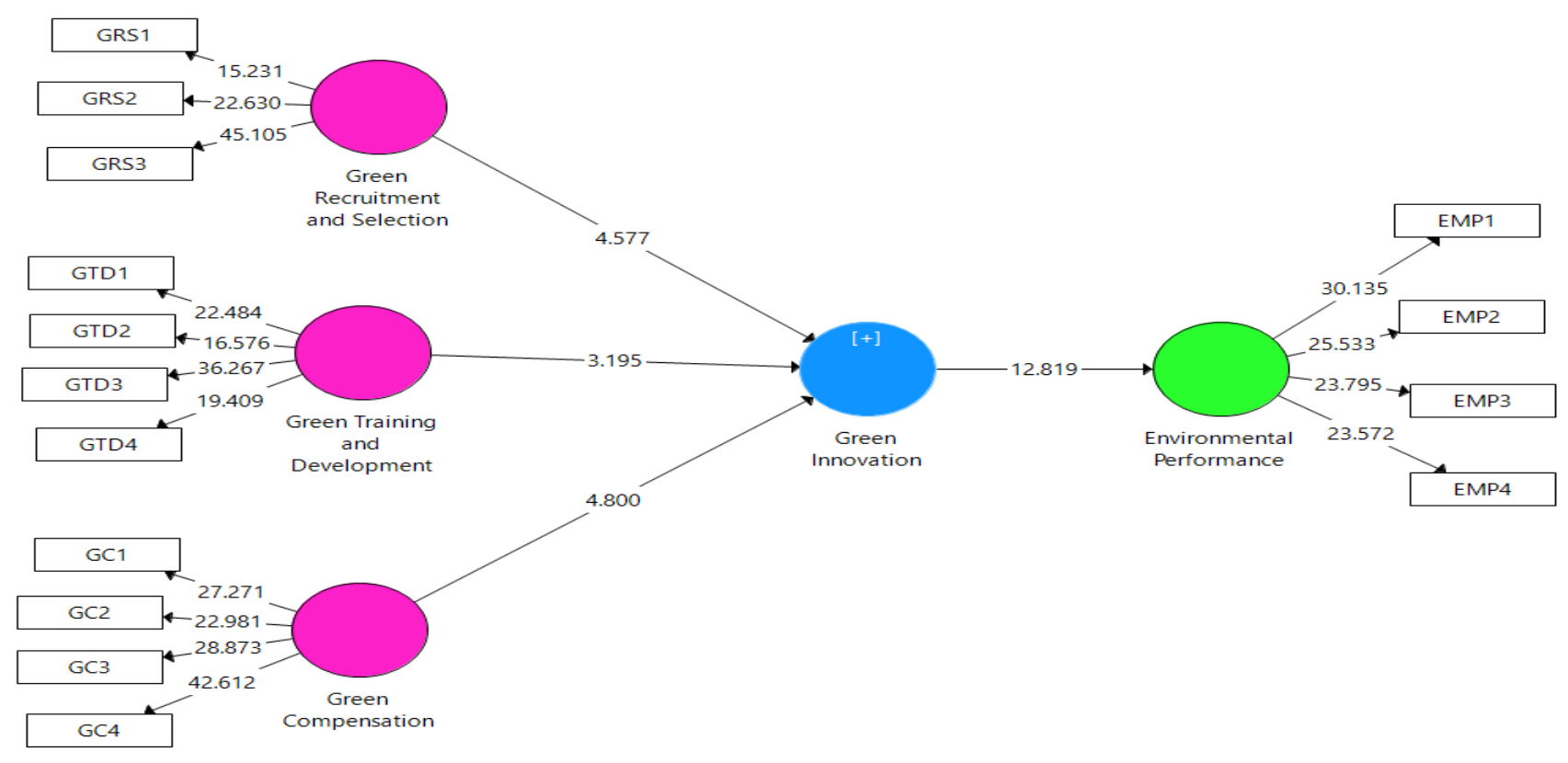

Figure 3: The structural model for indirect relationships 
Table 8: Effects Size

\begin{tabular}{lcc}
\hline Relationships & f square ${\left(\mathbf{f}^{2}\right.}^{\mathbf{l}}$ & Effect size \\
\hline GRS $\rightarrow$ EMP & 0.083 & Medium \\
GTD $\rightarrow$ EMP & 0.039 & Medium \\
GC $\rightarrow$ EMP & 0.125 & Medium \\
\hline
\end{tabular}

Note: EMP, environmental performance; GRS, green recruitment and selection; GTD, green training and development; GC, green compensation.

The effect size $\left(f^{\prime}\right)$ proposed by Cohen (1988) was next assessed. The guidelines proposed are 0.02 for small effects, 0.15 for medium effects, and 0.35 for large effects (Cohen, 1988). Table 8 indicates that all the direct relationships had medium effects.

Table 9: Predictive Relevance

\begin{tabular}{lccc}
\hline Constructs & R square $\left.\mathbf{( R}^{\mathbf{2}}\right)$ & Adjusted $\mathbf{R}^{\mathbf{2}}$ & $\mathbf{Q}$ square $\left(\mathbf{Q}^{\mathbf{2}}\right)$ \\
\hline EMP & 0.388 & 0.381 & 0.269 \\
\hline
\end{tabular}

Note: EMP, environmental performance.

Table 9 reveals the model's values for $\mathrm{R}$ square $\left(\mathrm{R}^{2}\right)$, Adjusted $\mathrm{R}^{2}$, and $\mathrm{Q}$ square $\left(\mathrm{Q}^{2}\right)$. From Table 9 , it can be seen that an R square value of 0.388 explains a total variance of $38.8 \%$ between GRS, GTD, and GC in EMP. This value is higher than 0.26 , which is a benchmark value proposed by Cohen (1988), and it indicates that the model is substantial. Chin et al. (2008) assert that when the $\left(Q^{2}\right)$, which is the predictive sample reuse technique, is evaluated together with both $\mathrm{R}^{2}$ and $f^{2}$, they effectively present the predictive relevance of the model. The $Q^{2}$ is generated through a blindfolding technique and reveals the usefulness of data in terms of reassembling them practically via the study model and the PLS features, thus, cross-validated redundancy measures. According to Chin et al. (2008), when the $Q^{2}$ value is greater than zero (0), the model is classified as having high predictive power. However, when the $Q^{2}$ value is below zero (0), it means the study's model lacks predictive relevance. So, the $Q^{2}$ value of 0.269 presented in Table 9 proposes that the study's model has a remarkable predictive relevance.

Table 10: PLS Assessment of Manifest Variable (Original Model)

\begin{tabular}{lcccc}
\hline Items & PLS-RMSE & $\boldsymbol{Q}^{2}$ predict & LM-RMSE & (PLS-RMSE)-(LM-RSME) \\
\hline EMP1 & 0.569 & 0.169 & 0.575 & -0.006 \\
EMP2 & 0.660 & 0.229 & 0.668 & -0.008 \\
EMP3 & 0.572 & 0.289 & 0.580 & -0.008 \\
EMP4 & 0.689 & 0.211 & 0.709 & -0.002 \\
\hline
\end{tabular}

Note: RMSE, root mean squared error; LM, linear model; EMP, environmental performance.

Following the guidelines recommended by Shmueli et al. (2019), the PLS predict of the model was assessed. To begin with this analysis, the PLS-SEM $Q^{2}$ predict values are first evaluated. PLS predict indicates a highly symmetrical distribution in prediction errors when the $\mathrm{Q}^{2}$ values are greater than zero $(0)$. Table 10 illustrates that the $Q^{2}$ predict figures are bigger than zero, suggesting that the PLS-RMSE values should be compared with the LM-RMSE as pointed by Shmueli et al. (2019). After the comparison, we realized that the PLS-SEM analysis produced a lower forecast error for all the indicators as seen in the EMP1, EMP2, EMP3, and EMP4 bearing $0.569,0.660,0.572$, and 0.689 , respectively. In contrast, LM produced RMSE figures of $0.575,0.668,0.580$, and 0.709 , respectively, for the model estimation using PLS-RMSE. So, the negative values obtained in Table 10 after deducting the PLS-RMSE values from the LM-RMSE values indicated a high predictive power of the model, supporting those of Ahakwa et al. (2021c), Quagraine et al. (2021), and (Odai et al., 2021). 


\section{Discussion}

The study aimed to analyze GHRM practices in Ghana's EMP in the manufacturing sector. The role of GI. The findings disclosed that GRS significantly and positively affected EMP. The positive interaction means that as GRS increases or decreases, so will EMP increase or decrease and vice versa. The significant interaction implies that GRS had a material impact on EMP of manufacturing industries in Ghana. This signpost that businesses must recruit candidates with a green approach and therefore engage in individuals who are already environmentally friendly and are used to environmental sustainability, such as waste management and recycling, to improve EMP. In turn, these people will aid manufacturing industries to realize their EMP. The outcome of this study is comparable to some past studies that found GRS to be an essential determinant of EMP (Kim et al., 2019; Rawashdeh, 2018; Yusoff et al., 2020).

Also, the findings disclosed that GTD has a significant positive effect on EMP. A rise or decline in GTD results in a rise or decline in EMP and vice versa substantially. To make EMP part of the company's beliefs, industrial firms need to offer personnel environmental education to increase their awareness of the environment and appreciate the environment. As this strengthens the employee's knowledge base and contributes to a deeper understanding of their environmental and business priorities or goals. More fantastic support was reported in several prior studies, which found GTD critical in influencing EMP (Abuelhassan and Elsayed, 2020; Rawashdeh, 2018; Yusoff et al., 2020).

Moreover, this study's results show that GC has a substantial positive influence on EMP. This implies that an increase or decrease in GC will increase or decrease EMP and vice versa. The significant impact implies that GC has a substantial effect on EMP of manufacturing industries. This indicates that rewards would increase workers' awareness in the workplace to the full and encourage them to attempt to meet the organization's goals. Moreover, manufacturing firms should encourage environmentally-friendly activities and produce goods and processes through a successful incentive scheme, thus increasing customer loyalty. This study's findings are consistent with previous studies that found GC as a significant driver of EMP (Arulrajah and Opatha, 2016; Rawashdeh, 2018; Saeed et al., 2018).

The findings disclosed that GI significantly and positively mediates GHRM practices (GRS, GTD, and GC) and EMP. This finding is in line with former research that shows GHRM practices significantly affects GI (Guerci et al., 2016; Singh et al., 2020), wherein innovating green products and processes significantly reduce the organization's negative impact on the environment and increases business efficiency by reducing waste and costs, saving money, time and energy, financial, environmental, and social success (El-Kassar and Singh, 2019; Karabulut, 2019; Singh et al., 2019).

All the three GHRM practices (GRS, GTD, and GC) had significant effects on environmental performance. This suggests that GHRM practices must be employed as a multidimensional variable that can improve environmental performance. The influences of GHRM practices on environmental performance were not equal; as a result, GC had the most significant influence on environmental performance, followed by GRS and last GTD. Nevertheless, all the three GHRM practices (GRS, GTD, and GC) need to function in synergy to achieve the desired result. This result highlights the importance of organizations promoting environmentallyfriendly activities in producing goods and services through an effective incentive system. Additionally, the ability of management to select the right person, thus, recruiting employees who have afore-knowledge about environmental values, designing, and promoting employees' environmental training, enhances green innovation and environmental performance. 


\section{Conclusion}

This research looked at the relationship between GHRM practices and EMP in Ghana, considering green innovation's mediation role. More specialized structural equation estimation techniques were used for the analysis to uncover accurate and valid results. Preliminary checks were done to determine whether the variables met internal consistency reliability, Composite reliability, and average variance extracted. All the study variables surpassed the threshold value for internal consistency reliability, composite reliability, and average variance extracted from the outcome. Also, a preliminary check was done to find out whether the study variables could be used together or not. The outcome of the test revealed no multicollinearity problem in the study model. According to the findings of Fornell-Larcker's discriminant validity and Heterotrait-Monotrait Ratio (HTMT) discriminant validity, there was no discriminant validity problem in the study variables. Next, structural equation regression estimation was employed to investigate the effect connection between the variables. The outcomes showed that GRS, GTD, and GC had a significant positive effect on EMP. Also, it was revealed that GC had the highest impact on EMP, followed by GRS and last GTD. Furthermore, GI significantly and positively mediated the association between GHRM practices and EMP. The study finally evaluated the predictive relevance of the study model, and from the outcome, the model has high predictive power. The techniques employed in this study indicate that the findings are accurately sufficient to be regarded for theoretical and practical implications. As a result, theoretical and practical implications were discussed.

\section{Theoretical Implications}

In line with the study's expectations, it was found that GHRM practices have a significant positive relationship with EMP. Also, GI significantly and positively mediates the association amid GHRM practices and EMP. This research will add to the works on GHRM practices and EMP in Ghana's manufacturing sector, and other developing countries can emulate. Again, the research is vital to the academic field because it will guide students and other researchers in similar fields of study.

\section{Practical Implications}

Our findings give executives, administrators, and organizations a set of critical suggestions for making green innovation happen and using it to beat competitors in the markets for superior environmental performance.

First, we claim that it is beneficial for organizations to achieve a positive image in consumers' minds by engaging in environmental protection. It has become more demanding, and organizations need to drive green in producing goods and services. Our study findings recommend that organizations prioritize and improve the green leadership habits needed for GHRM activities to be implemented. GHRM activities are critical in recruiting, increasing, and retaining workers who help the company's strategy cope with competition through green processes and green products. Additionally, organizations should recognize GHRM practices as a competitive benefit in channeling human capability to its environmental management efforts. Therefore, our research implies that organizations should incorporate GHRM practices in the corporate's multidimensional social systems to make human capital useful enough to improve EMP. We argued that GHRM practices are the organization's strategic direction to sustainable protection and allow staff to show green work methods to reduce environmental emissions. Therefore, we propose that management in charge of manufacturing organizations should balance environmental management objectives with GHRM practices and policies to encourage and withstand green processes and product innovation based on our research findings. Furthermore, our research suggests that authorities, corporate executives, and managers will see green innovation as a competitive opportunity and use it to fulfill environmental management targets. 


\section{Limitations and Recommendations}

The research has some limitations, and they are addressed along with guidance for future studies. First, we conducted this research in Ghana's small and medium-sized manufacturing enterprises, restricting our study's generalization to non-small and medium-sized manufacturing enterprises. Subsequent research can resolve the limitations identified by replicating similar research in other geographical locations globally to generalize the analysis. Variables used in this study work with a broader sample size can also be retested for further research so that the findings are applied to larger populations.

Abbreviations: Environmental Performance (EMP), Green Recruitment and Selection (GRS), Green Training and Development (GTD), Green Compensation (GC), Green Innovation (GI), Green Human Resource Management (GHRM), Human Resource Management (HRM), Human Resource (HR), Human Capital (HC), Root Mean Squared Error (RMSE), Linear Model (LM), Partial Mediation (PM), Heterotrait-Monotrait (HTMT), Average Variance Extracted (AVE), Variance Inflation Factor (VIF), Partial Least Squares (PLS), Structural Equation Modelling (SEM), Common Method Bias (CMB).

Funding: This research received no external funding.

Conflicts of Interest: The authors declare no conflict of interest.

\section{References}

Abuelhassan, A. E., \& Elsayed, Y. N. M. (2020). The Impact of Employee Green Training on Hotel Environmental Performance in the Egyptian Hotels. International Journal on Recent Trends in Business and Tourism (IJRTBT), 4(1), 24-33.

Ahakwa, I., Yang, J., Agba Tackie, E., Afotey Odai, L., \& Dartey, S. (2021a). The Effects of Job Autonomy, Organizational Learning, and Work Environment on Organizational Commitment of Public Sector Employees in the Ashanti Region of Ghana. International Journal of Scientific Research and Management, 9(1), 2099-2110. doi:10.18535/ijsrm/v9i1.em02

Ahakwa, I., Yang, J., Agba Tackie, E., \& Atingabili, S. (2021b). The Influence of Employee Engagement, Work Environment and Job Satisfaction on Organizational Commitment and Performance of Employees: A Sampling Weights in PLS path Modelling. SEISENSE Journal of Management, 4(3), 34-62. doi:10.33215/sjom.v4i3.641

Ahakwa, I., Yang, J., Agba Tackie, E., \& Bankole, K. (2021c). Exploring the Impact of Traditional Communication Channels on Customer Purchase Decision: A Case Study of University Students in Ghana. SEISENSE Business Review, 1(1), 31-44. doi:10.33215/sbr.v1i1.561

Ahmed, U., AlZgool, M. R. H., \& Shah, S. M. M. (2019). The impact of green human resource practices on environmental sustainability. Polish Journal of Management Studies, 20.

Albort-Morant, G., Leal-Millán, A., Cepeda-Carrion, G., \& Henseler, J. (2018). Developing green innovation performance by fostering of organizational knowledge and coopetitive relations. Review of managerial science, 12(2), 499-517.

Allameh, S. M., \& Khalilakbar, R. (2018). Exploring the antecedents of innovation performance: the roles of entrepreneurial orientation, learning orientation and organisational learning. International Journal of Business Excellence, 14(4), 470-485.

Alonso-Almeida, M. d. M., Bagur-Femenias, L., Llach, J., \& Perramon, J. (2018). Sustainability in small tourist businesses: the link between initiatives and performance. Current Issues in Tourism, 21(1), 1-20.

Ansari, N. Y., Farrukh, M., \& Raza, A. (2020). Green human resource management and employees proenvironmental behaviours: Examining the underlying mechanism. Corporate Social Responsibility and Environmental Management. 
Aragão, C. G., \& Jabbour, C. J. C. (2017). Green training for sustainable procurement? Insights from the Brazilian public sector. Industrial and Commercial Training.

Aranganathan, P. (2018). GREEN RECRUITMENT: A NEW-FANGLED APPROACH TO ATTRACT AND RETAIN TALENT. International Journal of Business Management and Research (IJBMR), 8(2), 69-76.

Arulrajah, A. A., \& Opatha, H. (2016). Analytical and theoretical perspectives on green human resource management: A simplified underpinning.

Bour, K. B., Asafo, A. J., \& Kwarteng, B. O. (2019a). Study on the effects of sustainability practices on the growth of manufacturing companies in urban Ghana. Heliyon, 5(6), e01903.

Bour, K. B., Mensah, H. K., Asafo, A. J., \& Dapaah, J. M. (2019b). Socio-economic Performance of Manufacturing Companies in Urban Ghana.

Chan, E. S., \& Hsu, C. H. (2016). Environmental management research in hospitality. International Journal of Contemporary Hospitality Management.

Chaudhary, R. (2018). Can green human resource management attract young talent? An empirical analysis. Paper presented at the Evidence-based HRM: A Global Forum for Empirical Scholarship.

Cheema, S., \& Javed, F. (2017). The effects of corporate social responsibility toward green human resource management: The mediating role of sustainable environment. Cogent Business \& Management, 4(1), 1310012.

Chen, Y.-S., Lai, S.-B., \& Wen, C.-T. (2006). The influence of green innovation performance on corporate advantage in Taiwan. Journal of business ethics, 67(4), 331-339.

Chin, W. W., Peterson, R. A., \& Brown, S. P. (2008). Structural equation modeling in marketing: Some practical reminders. Journal of Marketing theory and Practice, 16(4), 287-298.

Chiu, C. L., Zhang, J., Li, M., Wei, S., Xu, S., \& Chai, X. (2020). A study of environmental disclosures practices in Chinese energy industry. Asian Journal of Sustainability and Social Responsibility, 5, 1-21.

Cohen, S. (1988). Perceived stress in a probability sample of the United States.

Conway, J. M., \& Lance, C. E. (2010). What reviewers should expect from authors regarding common method bias in organizational research. Journal of Business and Psychology, 25(3), 325-334.

Daily, B. F., Bishop, J. W., \& Massoud, J. A. (2012). The role of training and empowerment in environmental performance. International Journal of Operations \& Production Management.

Dangelico, R. M., Pujari, D., \& Pontrandolfo, P. (2017). Green product innovation in manufacturing firms: A sustainability-oriented dynamic capability perspective. Business strategy and the Environment, 26(4), 490-506.

De Winne, S., \& Sels, L. (2010). Interrelationships between human capital, HRM and innovation in Belgian start-ups aiming at an innovation strategy. The International Journal of Human Resource Management, 21(11), 1863-1883.

Dormann, C. F., Elith, J., Bacher, S., Buchmann, C., Carl, G., Carré, G., . . Leitao, P. J. (2013). Collinearity: a review of methods to deal with it and a simulation study evaluating their performance. Ecography, 36(1), 27-46.

Dubey, R., Gunasekaran, A., Helo, P., Papadopoulos, T., Childe, S. J., \& Sahay, B. (2017). Explaining the impact of reconfigurable manufacturing systems on environmental performance: The role of top management and organizational culture. Journal of cleaner production, 141, 56-66.

Dumont, J., Shen, J., \& Deng, X. (2017). Effects of green HRM practices on employee workplace green behavior: The role of psychological green climate and employee green values. Human resource management, 56(4), 613-627.

El-Kassar, A.-N., \& Singh, S. K. (2019). Green innovation and organizational performance: the influence of big data and the moderating role of management commitment and HR practices. Technological Forecasting and Social Change, 144, 483-498.

Feng, Z., \& Chen, W. (2018). Environmental regulation, green innovation, and industrial green development: An empirical analysis based on the Spatial Durbin model. Sustainability, 10(1), 223. 
Fornell, C., \& Larcker, D. F. (1981). Evaluating structural equation models with unobservable variables and measurement error. Journal of marketing research, 18(1), 39-50.

Fu, X. (2015). China's path to innovation: Cambridge University Press.

Ghosh, P., Mukhopadhyay, A., Chanda, A., Mondal, P., Akhand, A., Mukherjee, S., . . Ghosh, T. (2017). Application of Cellular automata and Markov-chain model in geospatial environmental modeling-A review. Remote Sensing Applications: Society and Environment, 5, 64-77.

Gilal, F. G., Ashraf, Z., Gilal, N. G., Gilal, R. G., \& Channa, N. A. (2019). Promoting environmental performance through green human resource management practices in higher education institutions: A moderated mediation model. Corporate Social Responsibility and Environmental Management, 26(6), 1579-1590.

Grewal, R., Cote, J. A., \& Baumgartner, H. (2004). Multicollinearity and measurement error in structural equation models: Implications for theory testing. Marketing science, 23(4), 519-529.

Guerci, M., Longoni, A., \& Luzzini, D. (2016). Translating stakeholder pressures into environmental performance-the mediating role of green HRM practices. The International Journal of Human Resource Management, 27(2), 262-289.

Hair Jr, J. F., Hult, G. T. M., Ringle, C., \& Sarstedt, M. (2016). A primer on partial least squares structural equation modeling (PLS-SEM): Sage publications.

Hameed, Z., Khan, I. U., Islam, T., Sheikh, Z., \& Naeem, R. M. (2020). Do green HRM practices influence employees' environmental performance? International Journal of Manpower.

Harrison, T., \& Bazzy, J. D. (2017). Aligning organizational culture and strategic human resource management. Journal of Management Development.

Henseler, J., Ringle, C. M., \& Sarstedt, M. (2015). A new criterion for assessing discriminant validity in variancebased structural equation modeling. Journal of the academy of marketing science, 43(1), 115-135.

Jabbour, C. J. C., \& de Sousa Jabbour, A. B. L. (2016). Green human resource management and green supply chain management: Linking two emerging agendas. Journal of Cleaner Production, 112, 1824-1833.

Jackson, S. E., \& Seo, J. (2010). The greening of strategic HRM scholarship. Organization Management Journal, 7(4), 278-290.

Jia, J., Liu, H., Chin, T., \& Hu, D. (2018). The continuous mediating effects of GHRM on employees' green passion via transformational leadership and green creativity. Sustainability, 10(9), 3237.

Karabulut, A. T. (2019). Antecedents and consequences of green innovation.

Kim, J. H. (2019). Multicollinearity and misleading statistical results. Korean journal of anesthesiology, 72(6), 558.

Kim, Y. J., Kim, W. G., Choi, H.-M., \& Phetvaroon, K. (2019). The effect of green human resource management on hotel employees' eco-friendly behavior and environmental performance. International Journal of Hospitality Management, 76, 83-93.

Kline, R. B. (2011). Convergence of structural equation modeling and multilevel modeling: na.

Kock, N. (2015). Common method bias in PLS-SEM: A full collinearity assessment approach. International Journal of e-Collaboration (ijec), 11(4), 1-10.

Korankye, B., Ahakwa, I., Anaman, E. A., \& Samuel, D. (2021). The influence of Personality Traits on Organizational Commitment: Evidence from GCB Bank in Ghana. Journal of Research in Business and Management, 9(1), 01-15.

Longoni, A., Luzzini, D., \& Guerci, M. (2018). Deploying environmental management across functions: the relationship between green human resource management and green supply chain management. Journal of Business Ethics, 151(4), 1081-1095.

Masri, H. A., \& Jaaron, A. A. (2017). Assessing green human resources management practices in Palestinian manufacturing context: An empirical study. Journal of cleaner production, 143, 474-489.

Melnyk, S. A., Sroufe, R. P., \& Calantone, R. (2003). Assessing the impact of environmental management systems on corporate and environmental performance. Journal of operations management, 21(3), 329-351. 
Mishra, P. (2017). Green human resource management: A framework for sustainable organizational development in an emerging economy. International Journal of Organizational Analysis, 25(5), 762-788.

Mwita, K. M., \& Kinemo, S. M. (2018). The Role of Green Recruitment and Selection on Performance of Processing Industries in Tanzania: A Case of Tanzania Tobacco Processors Limited (TTPL). International Journal of Human Resource Studies, 8(4).

Nejati, M., Rabiei, S., \& Jabbour, C. J. C. (2017). Envisioning the invisible: Understanding the synergy between green human resource management and green supply chain management in manufacturing firms in Iran in light of the moderating effect of employees' resistance to change. Journal of Cleaner Production, 168, 163-172.

Odai, L. A., Yang, J., Ahakwa, I., Mohammed, S. I., \& Dartey, S. (2021). Determining the Impact of Supervisory Support on Employee Engagement in the Telecommunication Sector of Ghana: The Role of Supportive Organizational Culture. SEISENSE Business Review, 1(2), 15-31. doi:10.33215/sbr.v1i2.588

Paillé, P. (2019). Green recruitment and selection: an insight into green patterns. International Journal of Manpower.

Pham, N. T., Thanh, T. V., Tučková, Z., \& Thuy, V. T. N. (2020). The role of green human resource management in driving hotel's environmental performance: Interaction and mediation analysis. International Journal of Hospitality Management, 88, 102392.

Quagraine, N. E., Li, C., Ahakwa, I., \& Quagraine, N. A. (2021). Dynamic Capabilities and Competitive Advantage of Telecommunication Companies in Ghana. The Role of Innovation Capability. International Journal of Scientific Research in Computer Science, Engineering and Information Technology, 7(3), 146-160. doi:http://doi.org/10.32628/cseit217314

Raab, C., Baloglu, S., \& Chen, Y.-S. (2018). Restaurant managers' adoption of sustainable practices: An application of institutional theory and theory of planned behavior. Journal of foodservice business research, $21(2), 154-171$.

Ramasamy, A. (2017). A study on implications of implementing green HRM in the corporate bodies with special reference to developing nations.

Rawashdeh, A. (2018). The impact of green human resource management on organizational environmental performance in Jordanian health service organizations. Management Science Letters, 8(10), 1049-1058.

Renwick, D. W., Redman, T., \& Maguire, S. (2013). Green human resource management: A review and research agenda. International journal of management reviews, 15(1), 1-14.

Roscoe, S., Subramanian, N., Jabbour, C. J., \& Chong, T. (2019). Green human resource management and the enablers of green organisational culture: Enhancing a firm's environmental performance for sustainable development. Business Strategy and the Environment, 28(5), 737-749.

Saeed, A., Jun, Y., Nubuor, S. A., Priyankara, H. P. R., \& Jayasuriya, M. P. F. (2018). Institutional pressures, green supply chain management practices on environmental and economic performance: A two theory view. Sustainability, 10(5), 1517.

Saeed, B. B., Afsar, B., Hafeez, S., Khan, I., Tahir, M., \& Afridi, M. A. (2019). Promoting employee's proenvironmental behavior through green human resource management practices. Corporate Social Responsibility and Environmental Management, 26(2), 424-438.

Shmueli, G., Sarstedt, M., Hair, J. F., Cheah, J.-H., Ting, H., Vaithilingam, S., \& Ringle, C. M. (2019). Predictive model assessment in PLS-SEM: guidelines for using PLSpredict. European Journal of Marketing.

Singh, S. K., Chen, J., Del Giudice, M., \& El-Kassar, A.-N. (2019). Environmental ethics, environmental performance, and competitive advantage: role of environmental training. Technological Forecasting and Social Change, 146, 203-211.

Singh, S. K., Del Giudice, M., Chierici, R., \& Graziano, D. (2020). Green innovation and environmental performance: The role of green transformational leadership and green human resource management. Technological Forecasting and Social Change, 150, 119762. 
Siyambalapitiya, J., Zhang, X., \& Liu, X. (2018). Green human resource management: A proposed model in the context of Sri Lanka's tourism industry. Journal of cleaner production, 201, 542-555.

Sobaih, A. E. E., Hasanein, A., \& Elshaer, I. (2020). Influences of green human resources management on environmental performance in small lodging enterprises: The role of green innovation. Sustainability, 12(24), 10371.

Tackie, E. A., Chen, H., Ahakwa, I., Atingabilli, S., Ansah, K. A., \& Baku, R. (2020). Integration of Economic, Educational and Socio-Cultural Capabilities for Rural Poverty Alleviation in Northern Ghana. Integration, 5(1).

Tariq, A., Badir, Y., \& Chonglerttham, S. (2019). Green innovation and performance: moderation analyses from Thailand. European Journal of Innovation Management.

Teixeira, A. A., Jabbour, C. J. C., de Sousa Jabbour, A. B. L., Latan, H., \& De Oliveira, J. H. C. (2016). Green training and green supply chain management: evidence from Brazilian firms. Journal of Cleaner Production, $116,170-176$.

Varghese, S. (2019). A review on green innovation practices and its impact on various performance levels. Journal of the Gujarat Research Society, $21(8), 340-347$.

Wahab, M. Z. H., \& Othman, K. (2021). Impact of COVID-19 on Student's Emotional and Financial Aspects in the Higher Learning Institutions. SEISENSE Journal of Management, 4(4), 1-15.

Wahab, M. Z. H., \& Tajuddin, A. M. (2020). The Roles of Health Awareness and Knowledge in Medical Takaful Purchase Intention. International Journal of Banking and Finance, 14, 95-116.

Yafi, E., Tehseen, S., \& Haider, S. A. (2021). Impact of Green Training on Environmental Performance through Mediating Role of Competencies and Motivation. Sustainability, 13(10), 5624.

Ying, F., Dartey, S., Ahakwa, I., Odai, L. A., Bright, D., \& Amoabeng, S. M. (2021). Ascertaining the Perceived Risks and Benefits of Social Media Usage on the Behavioural Intent of Employees: Study of the Banking Sectors in Ga-West Municipality: Mediating Role of User Satisfaction.

Yuriev, A., Boiral, O., Francoeur, V., \& Paillé, P. (2018). Overcoming the barriers to pro-environmental behaviors in the workplace: A systematic review. Journal of Cleaner Production, 182, 379-394.

Yusoff, Y. M., Nejati, M., Kee, D. M. H., \& Amran, A. (2020). Linking green human resource management practices to environmental performance in hotel industry. Global Business Review, 21 (3), 663-680.

Zoogah, D. B. (2018). High-performance organizing, environmental management, and organizational performance: An evolutionary economics perspective. Human resource management, 57(1), 159-175. 